\title{
Keputusan Penggunaan Jasa Perbankan Syariah: Perspektif Nasabah Milenial
}

\author{
Ida Syafrida1, Aminah², Taufik Awaludin ${ }^{3}$ \\ Politeknik Negeri Jakarta ${ }^{1}$, Politeknik Negeri Jakarta ${ }^{2}$, Universitas \\ Pamulang ${ }^{3}$ \\ Ida.syafrida@akuntansi.pnj. ac.id ${ }^{1}$, aminah@akuntansi.pnj.ac. id ${ }^{2}$, \\ dosen01844@unpam.ac.id ${ }^{3}$
}

\begin{abstract}
This study aims to identify the party and the dominant aspects that influence millennial customers in using Islamic banking services and provide relevant recommendations. The research problem is because the role of Islamic banking has not been optimal in the national economy due to the low market share and small number of deposits. This is due to the low scale of the Islamic banking industry. Market share growth is also influenced by the growth in the number of Third Party Funds. To increase customer users, Islamic banks should innovate in knowing the needs, desires, tastes and behavior of customers so that they trust and be a loyal customers. One of the user segmentation is millennial society so this object research is millennial customer respondents. The research method is descriptive analysis, factor analysis and mean analysis. The results of study found that those who influence millennial customers in using Islamic banking services are majority on their own initiative. The dominant aspect that affects millennial customers in using Islamic banking services is the perception of reputation and the availability of networks and technology. The subaspect of the dominant perception of reputation is religious reputation or the principle of sharia conformity. The dominant aspect of network availability and technology is the availability of SMS/internet/online banking. Limitations of this study are related to the search for previous research literature that discusses respondents with millennial age segmentation is still few.
\end{abstract}

Keywords: Islamic Banking, Decision, Millennial Customers

\begin{abstract}
Abstrak
Penelitian ini bertujuan mengidentifikasi pihak dan aspek dominan yang memengaruhi nasabah milenial dalam menggunakan jasa perbankan syariah dan memberikan rekomendasi yang relevan. Permasalahan penelitian dilatarbelakangi belum optimalnya peran perbankan syariah dalam perekonomian nasional karena pangsa pasar yang masih rendah, jumlah DPK yang masih sedikit.Hal ini disebabkan masih rendahnya skala industri perbankan syariah. Pertumbuhan market share juga dipengaruhi oleh pertumbuhan jumlah Dana Pihak Ketiga (DPK). Untuk meningkatkan jumlah nasabah penggunanya, bank syariah harus berinovasi dalam mengetahui kebutuhan, keinginan, selera dan perilaku nasabah sehingga mereka percaya dan loyal menjadi nasabah pengguna. Salah satu segmentasi pengguna adalah masyarakat milenial sehingga penelitian ini memiliki objek responden nasabah milenial. Metode penellitian yang digunakan adalah analisis deskriptif, analisis faktor dan analisis mean. Hasil penelitian ini menemukan bahwa pihak yang memengaruhi nasabah milenial dalam menggunakan jasa perbankan syariah dominan atas inisiatif diri sendiri.Aspek dominan yang memengaruhi nasabah
\end{abstract}


milenial dalam menggunakan jasa perbankan syariah adalah persepsi reputasi dan ketersediaan jaringan dan teknologi. Sub aspek dari persepsi reputasi yang dominan adalah reputasi keagamaan atau prinsip kesesuaian syariah. Sub aspek ketersediaan jaringan dan teknologi yang dominan adalah ketersediaan SMS/internet/online banking. Keterbatasan penelitian ini terkait pencarian literatur penelitian sebelumnya yang membahas responden dengan segmentasi umur milenial masih sedikit jumlahnya.

Kata Kunci: Bank Umum Syariah, Keputusan, Nasabah Milenial

\section{PENDAHULUAN}

Perbankan syariah merupakan industri keuangan syariah yang paling berkembang di Indonesia dibanding industri pasar modal syariah dan industri keuangan non bank syariah. Berdasarkan data Statistik OJK (2018), sampai dengan akhir September 2018 jaringan perbankan syariah di Indonesia terdiri 14 entitas Bank Umum Syariah (BUS), 20 entitas Unit Usaha Syariah (UUS) dan 168 entitas Bank Pembiayaan Rakyat Syariah (BPRS). Adapun jaringan perbankan syariah tersebut mencakup 1.862 unit kantor BUS, 340 unit kantor UUS dan 468 unit kantor BPRS. Jumlah jaringan perbankan tersebut masih kalah jumlah, apabila dibandingkan dengan jumlah jaringan perbankan konvensional. Adapun jaringan perbankan konvensional terdiri dari 116 entitas Bank Umum Konvensional (BUK) dan 1.636 entitas Bank Perkreditan Rakyat (BPR). Jaringan perbankan konvensional tersebut mencakup 32.730 unit kantor BUK dan 6.075 unit kantor BPR. Dari data tersebut, menyimpulkan jaringan perbankan syariah, dilihat dari jumlah kantor hanya mencapai 7,02\% dibandingkan dengan jumlah kantor perbankan konvensional.

Namun, secara empiris perbankan syariah dapat lebih mengoptimalkan peranan intermediasi dalam menyalurkan pembiayaan dibandingkan dengan kredit yang disalurkan oleh perbankan secara keseluruhan. Selama tahun 2014-2017, rata-rata FDR (Financing Deposit Ratio) perbankan syariah pada kisaran 111\%, sedangkan pada industri perbankan secara keseluruhan berkisar $82 \%$. Peranan intermediasi tersebut turut membantu pertumbuhan ekonomi pada sektor riil dimana bank syariah dapat berperan sebagai commercial banking dan investment banking. Untuk lebih meningkatkan kontribusi ekonomi tersebut, tentu perbankan syariah harus juga meningkatkan market sharenya. Akan tetapi, hingga akhir September 2018 market share perbankan syariah dalam industri perbankan nasional baru 5,93\% (OJK 2018). Perbankan syariah harus berupaya lebih keras untuk meningkatkan pangsa pasar dengan menarik sebanyak-banyaknya nasabah bank untuk bertransaksi di bank syariah. Dengan demikian bank syariah dapat beroperasi dengan lebih efisien dan dapat bersaingdengan bank konvensional.Salah satu segmentasi pasar yang potensial adalah segmentasi masyarakat milenial.

Berdasarkan data BPS September 2018, jumlah penduduk di Indonesia berdasarkan klasifikasi agama, mayoritas beragama Islam (lebih dari 80\%). Kemudian jika penduduk diklasifikasikan berdasarkan umur, Indonesia 
memiliki penduduk mayoritas berusia muda atau produktif yaitu berjumlah 181 juta jiwa. Jumlah penduduk usia produktif di Indonesia lebih banyak dibandingkan lima negara Asia lainnya penghasil produk domestik bruto (PDB) besar seperti China, Jepang, India dan Korea. Penduduk usia produktif adalah penduduk yang berusia 15-64 tahun. Pada tahun 2045 diperkirakan akan mencapai 208 juta jiwa. Dari klasifikasi penduduk usia produktif tersebut, lebih dari 90 juta jiwa merupakan generasi milenial yang lahir antara tahun 1981 hingga 2000. Hal ini yang menyebabkan generasi milenial menjadi segmentasi pasar bisnis yang potensial untuk menggunakan produkproduk keuangan syariah termasuk produk perbankan syariah.

Riset ini secara umum bertujuan untuk mengidentifikasi pihak dan aspek dominan yang memengaruhi masyarakat milenial dalam menggunakan jasa perbankan syariah. Adapun riset-riset sebelumnya terkait faktor determinan dalam menggunakan jasa perbankan syariah lebih banyak menggunakan responden masyarakat umum. Dalam riset ini nasabah yang menjadi objek penelitian adalah nasabah milenial yang berdomisili atau beraktifitas di wilayah Jakarta, Bogor, Depok, Tangerang dan Bekasi. Pertimbangan objek wilayah tersebut karena sebagian besar generasi milenial beraktifitas di wilayah perkotaan. Kemudian riset ini juga secara khusus akan memberikan rekomendasi upaya penguatan persepsi masyarakat milenial terhadap perbankan syariah guna meningkatkan pengguna jasa perbankan syariah.

\section{KAJIAN LITERATUR}

\section{Generasi Milenial}

Menurut Ali et al., (2017), generasi milenial adalah mereka yang lahir antara tahun 1981 sampai dengan tahun 2000. Sebelum generasi milenial ada Generasi X yang menurut pendapat para peneliti lahir pada rentang tahun 1960-1980. Generasi ini cenderung menyukai risiko dan pengambilan keputusan yang matang akibat dari pola asuh dari generasi sebelumnya (Baby Boomers), sehingga nilai-nilai pengajaran dari generasi baby boom masih melekat. Berikutnya adalah generasi Baby Boom, yaitu generasi yang lahir pada rentang tahun 1946-1960. Generasi ini terlahir pada masa perang dunia kedua telah berakhir sehingga perlu penataan ulang kehidupan. Disebut Generasi Baby Boom karena di era tersebut kelahiran bayi sangat tinggi. Terakhir generasi tertua adalah yang sering disebut generasi veteran yang lahir kurang dari tahun 1946.

Hasil studi yang dilakukan oleh Boston Consulting Group (BCG) bersama University of Berkley tahun 2011 di Amerika Serikat tentang generasi milenial USA sebagai berikut; minat membaca secara konvensional kini sudah menurun karena Generasi $Y$ lebih memilih membaca lewat smartphone; milenial wajib memiliki akun sosial media sebagai alat komunikasi dan pusat informasi; milenial pasti lebih memilih ponsel daripada televisi; milenial menjadikan keluarga sebagai pusat pertimbangan dan pengambil keputusan mereka. 
Untuk menarik minat generasi milenial sebagai pengguna jasanya, perbankan syariah harus berkreasi dan berinovasi dalam mengetahui kebutuhan, keinginan, selera dan perilaku nasabah tersebut sehingga mereka percaya dan loyal menjadi nasabah pengguna jasa perbankan syariah.Bank syariah tentu harus memahami faktor kunci atau preferensi segmentasi nasabah tersebut.

\section{Kriteria Pemilihan Bank Syariah}

Sejumlah riset terdahulu telah mengungkapkan beberapa kriteria penggunaan jasa perbankan oleh nasabah, diantaranya Lateh et al., (2009), mengungkapkan bahwa masyarakat Thailand tahu bahwa karakteristik penting dari bank syariah adalah larangan bunga. Mereka cenderung mendukung gagasan bahwa bank syariah harus berusaha untuk mencapai tujuan sosialnya lebih dari tujuan komersial. Selain itu, hasil penelitian lain menunjukkan bahwa ada perbedaan antara preferensi pelanggan muslim Thailand dan non-muslim terhadap berbagai kriteria pemilihan bank. Orangorang Muslim sangat mempertimbangkan fasilitas tabungan tanpa bunga, sementara orang-orang non-Muslim cenderung lebih memperhatikan reputasi dan citra mereka, dan personel yang berpengetahuan dan kompeten. Kemudian Marimuthu et al., (2010) mengungkapkan hasil dari 8 kriteria prioritas nasabah dalam memilih bank syariah terkait profil. Kriteria keuntungan dan biaya menempati prioritas pertama, sedangkan faktor religi (keagamaan) menempati prioritas kelima dan faktor ukuran bank dan reputasi menempati prioritas keenam. Menurut Awan dan Bukhari (2011) mengungkapkan bahwa sebagian besar pelanggan bank syariah di Pakistan menilai fitur produk dan kualitas layanan sebagai faktor utama untuk menentukan pilihan bank syariah, dan kurang memberikan kepentingan pada kepercayaan agama sebagai faktor yang berpengaruh dalam memilih bank syariah. Hal itu juga sejalan dengan keputusan nasabah non muslim dalam memilih tabungan syariah di Indonesia (Hana, 2018). Mereka lebih mengutamakan pelayanan dan promosi yang dilakukan.

Hasan et al., (2012) mengungkapkan kriteria pemilihan bank syariah untuk konsumen yang beragam di Karachi, Pakistan. Sepuluh faktor yang meliputi kenyamanan, kualitas layanan oleh bank, motif keagamaan konsumen, ketersediaan ATM, privasi dan kerahasiaan, reputasi dan citra bank, variasi dalam pilihan pembiayaan, profit tinggi dan biaya layanan rendah, rekomendasi dari teman serta keluarga dan keramahan serta sikap responsif staf perbankan telah diambil untuk menyelidiki kriteria konsumen untuk memilih perbankan syariah. Temuan menunjukkan bahwa profit tinggi dan biaya layanan rendah adalah faktor yang paling penting diikuti oleh motif keagamaan dan kualitas layanan untuk memilih perbankan syariah oleh konsumen. Abhimantra et al., (2013) mengungkapkan bahwa faktor-faktor seperti pengetahuan, religiusitas, produk, reputasi dan pelayanan di Bank Syariah memiliki pengaruh positif terhadap keputusan memilih menabung di Bank Syariah. Sari et al., (2016) mengungkapkan temuan hasil bahwa faktor 
preferensi etnis Tionghoa terhadap Bank syariah di Indonesia, selain mempertimbangkan faktor maksimum profit, juga mempertimbangkan faktor riba (kesesuaian syariah). Etnis Tionghoa Non Muslim beragama Budha, Kristen dan Katholik, ternyata juga mengenal konsep larangan bunga dikalangan agama non muslim.

\section{METODE PENELITIAN}

Penelitian ini merupakan jenis penelitian kepustakaan dan survei dimana peneliti terlebih dahulu mengkaji kepustakaan yang berkaitan erat dengan permasalahan penelitian. Setelah itu, peneliti membuat kuisioner dan meminta sejumlah responden untuk menjawab kuisioner tersebut. Responden menjawab kuisioner tersebut berdasarkan Analisis Judgement sesuai dengan keyakinan responden tersebut terhadap pertanyaan dan pernyataan yang ada dalam kuisioner. Penelitian ini menggunakan studi kasus dengan objek penelitian nasabah milenial aktif pengguna jasa bank syariah berdomisili atau beraktifitas di wilayah Jakarta, Bogor, Depok, Tangerang dan Bekasi. Penelitian dilakukan selama periode April sampai dengan Juni 2019.

\section{Data dan Sumber Data}

Penelitian ini menggunakan data primer dan sekuner. Data sekunder didapat dari literatur buku, jurnal, tesis, disertasi yang menghasilkan sejumlah pertanyaan yang akan diajukan kepada responden dalam daftar isian kuisioner. Jawaban responden atas kuisioner yang diajukan merupakan data primer (lapangan) yang diolah oleh peneliti.

\section{Penentuan Sampel Responden}

Pemilihan responden dalam penelitian ini dilakukan secara purposive sampling dan non probability sampling yang ditujukan kepada nasabah nasabah milenial aktif pengguna jasa bank syariah yang berdomisili atau beraktifitas di wilayah Jakarta, Bogor, Depok, Tangerang dan Bekasi. Peneliti ingin mengetahui preferensi nasabah tersebut.

Sebanyak 300 kuisioner dibagikan kepada responden, namun yang dikembalikan kepada peneliti sebanyak 251 kuisioner. Dari 251 kuisioner tersebut diseleksi lagi dalam kriteria nasabah aktif (masih memiliki rekening) pada bank syariah dan tergolong nasabah milenial (berusia 18 sampai 38 tahun). Hasil kuisioner yang dapat diproses sebanyak 86 kuisioner atau $34,26 \%$ dari total responden yang didapat.

\section{Teknik Pengumpulan Data dan Informasi}

Pengumpulan data yang digunakan dengan melakukan kuisioner mandiri. Kuisioner berisi dua bagian; bagian pertama dirancang untuk mengumpulkan informasi tentang karakteristik sampel, demografi dan data ekonomi sampel. Pada bagian kedua, responden diminta untuk menjawab sejumlah pertanyaan kualitatif terkait preferensi mereka dalam menggunakan jasa bank. Adapun responden menjawab dengan skala linkert Lima Point dari skala sangat tidak signifikan (skala 1) sampai dengan sangat signifikan (skala 5). 


\section{Teknik Pengolahan dan Analisis Data}

Metode yang digunakan adalah analisa deskriptif, analisis faktor dan analisis mean. Analisis deskriptif berupaya mengungkapkan karakteristik, demografi dan data ekonomi responden dalam suatu bentuk penyajian data yang mudah dimengerti dan diterjemahkan. Analisis faktor berupaya mereduksi sejumlah elemen pertanyaan yang tidak signifikan dan membuat suatu klasifikasi dengan me-loading suatu entitas faktor sehingga dapat diketahui elemen dan faktor mana yang memiliki skala prioritas yang tinggi. Analisis faktor digunakan untuk mengidentifikasi 7 kriteria evaluatif (persepsi reputasi, kualitas layanan, daya tarik fisik, rasionalitas nasabah, internal bank/ karyawan, letak lokasi bank serta ketersediaan jaringan dan teknologi). Setelah itu analisis mean digunakan untuk mengungkapkan suatu bentuk penyajian data yang ringkas dengan mendapatkan nilai mean, distribusi frekuensi dan distribusi prosentase serta peringkat prioritas faktor. Setelah itu, peneliti melakukan interpretasi data dan membuat kesimpulan serta rekomendasi berdasarkan temuan penelitian.

\section{Analisis faktor}

Asumsi analisis faktor pertama adalah menguji matriks korelasinya (Uji Determinant of Correlation Matrix). Matrik korelasi antar variabel dinyatakan saling terkait apabila determinan bernilai mendekati nilai 0. Asumsi analisis faktor berikutnya adalah Uji Kaiser Meyer Olkin Measure of Sampling (KMO) dan Barlett Test of Spehricity. KMO adalah indeks perbandingan jarak antara koefisien korelasi dengan koefisien korelasi parsialnya. Jika jumlah kuadrat koefisen korelasi parsial di antara seluruh pasangan variabel bernilai kecil jika dibandingkan dengan jumlah kuadrat koefisien korelasi, maka akan menghasilkan nilai KMO mendekati 1. Nilai KMO dianggap mencukupi jika lebih dari 0,5. Selain itu, nilai MSA dan loading komunalitas tiap variabel pada faktor juga diatas 0,5 .

\section{PEMBAHASAN}

\section{Analisis Deskriptif}

Dalam analisa ini, akan memaparkan terkait seleksi responden, data demografi responden serta aspek dan variabel indikator penelitian yang digunakan. Berikut masing-masing penjelasannya:

\section{Data Demografi Responden}

Informasi demografi yang diperoleh dari responden termasuk gender, umur, agama, status pernikahan, pendidikan terakhir, jenis pekerjaan, jumlah pendapatan sebulan, dan kelompok nasabah bank syariah. Informasi ini diperlukan untuk menentukan bagaimana data demografi dapat dipertimbangkan dalam hal penilaian kriteria pemilihan bank dari nasabah milenial aktif pengguna jasa bank syariah. Berdasarkan data dari 86 responden yang dapat diproses, secara dominan memiliki kriteria: bergender wanita sebanyak 58,1 \%, berusia 25-38 tahun sebanyak 64,0\%, muslim sebanyak 98,8 \%, berstatus lajang sebanyak 69,8\%, telah tamat pendidikan diploma/sarjana sebanyak 72,1\%, bekerja sebagai pegawai swasta sebanyak 
62,8 \%, memiliki pendapatan antara $\mathrm{Rp} 4.000 .000$,- sampai dengan $\mathrm{Rp}$ 8.000.000,00 per bulan sebanyak 34,9 \% dan merupakan nasabah BNI Syariah sebanyak 38,4\%. Berikut data lengkap profil responden:

\section{Tabel 1}

Data Profil Responden

\begin{tabular}{|c|c|c|}
\hline Klasifikasi Variabel & Jumlah & Prosentase \\
\hline \multicolumn{3}{|l|}{ Gender $(n=86)$} \\
\hline Pria & 36 & 41,9 \\
\hline Wanita & 50 & 58,1 \\
\hline \multicolumn{3}{|l|}{$\operatorname{Umur}(\mathrm{n}=86)$} \\
\hline $18-24$ & 31 & 36,0 \\
\hline $25-38$ & 55 & 64,0 \\
\hline \multicolumn{3}{|l|}{ Agama $(n=86)$} \\
\hline Islam & 85 & 98,8 \\
\hline Protestan & 1 & 1,2 \\
\hline \multicolumn{3}{|l|}{ Status Pernikahan $(n=86)$} \\
\hline Lajang & 60 & 69,8 \\
\hline Menikah & 26 & 30,2 \\
\hline \multicolumn{3}{|l|}{ Pendidikan Terakhir $(\mathrm{n}=86)$} \\
\hline SMP/SMA & 10 & 11,6 \\
\hline Diploma/Sarjana & 62 & 72,1 \\
\hline Pascasarjana & 14 & 16,3 \\
\hline \multicolumn{3}{|l|}{ Jenis Pekerjaan $(n=86)$} \\
\hline Mahasiswa/i & 16 & 18,6 \\
\hline Pegawai Swasta & 54 & 62,8 \\
\hline Pegawai Negeri Sipil & 3 & 3,5 \\
\hline Pengusaha & 1 & 1,2 \\
\hline Lainnya & 12 & 13,9 \\
\hline \multicolumn{3}{|l|}{ Jumlah Pendapatan Sebulan $(n=86)$} \\
\hline$<\operatorname{Rp} 2.000 .000,00$ & 17 & 19,8 \\
\hline Rp 2.000.000,00 s.d Rp 4.000.000,00 & 27 & 31,4 \\
\hline $\operatorname{Rp} 4.000 .000,00$ s.d Rp 8.000.000,00 & 30 & 34,9 \\
\hline$>\operatorname{Rp} 8.000 .000,00$ & 12 & 13,9 \\
\hline \multicolumn{3}{|l|}{ Nama Bank Syariah $(\mathrm{n}=86)$} \\
\hline Bank Syariah Mandiri & 25 & 29,1 \\
\hline Bank Muamalat Indonesia & 15 & 17,4 \\
\hline BNI Syariah & 33 & 38,4 \\
\hline BRI Syariah & 6 & 7,0 \\
\hline Bank Syariah Lainnya & 7 & 8,1 \\
\hline
\end{tabular}

Pihak yang Mempengaruhi Masyarakat Milenial dalam Pengambilan Keputusan Menggunakan Jasa Perbankan Syariah

Berdasarkan hasil quesioner dari 86 data yang diterima, sejumlah 69 orang (80\%) menyatakan mengambil keputusan menggunakan jasa bank syariah atas inisiatif diri sendiri dan 17 orang (20\%) menyatakan atas referensi 
orang/pihak lain. Kemudian dari pertanyaan eksplorasi berikutnya mengenai pihak/orang lain yang memengaruhi; 10 orang (59\%) menjawab dipengaruhi oleh atasan/perusahaan; oleh saudara dan teman/sahabat masing-masing 2 orang (12\%); oleh orang tua, tokoh agama/pendidik, dan karyawan bank syariah masing-masing 1 orang (6\%).

Aspek dominan yang Mempengaruhi Masyarakat Milenial dalam Pengambilan Keputusan Menggunakan Jasa Perbankan Syariah Aspek dan Variabel Indikator Penelitian

Adapun aspek yang diidentifikasi dalam penelitian ini terkait penilaian kriteria pemilihan bank dari nasabah milenial aktif pengguna jasa bank syariah adalah: (1) persepsi reputasi, (2) kualitas layanan, (3) daya tarik fisik, (4) rasionalitas nasabah, (5) internal bank (karyawan), (6) letak lokasi bank dan (7) ketersediaan jaringan dan teknologi. Sebanyak 28 variabel indikator diperlukan untuk menjadi rincian bagi ketujuh aspek tersebut. Pada Tabel 2, di bawah ini adalah penjelasannya:

Tabel 2

Aspek dan Variabel Indikator Penelitian

\begin{tabular}{l}
\hline ASPEK DAN VARIABEL INDIKATOR \\
PERSEPSI REPUTASI \\
\hline 1. reputasi keagamaan (prinsip kesesuaian syariah/ menghindari riba) \\
\hline 2. reputasi keuangan (kinerja bank) \\
\hline 3. reputasi bank (ukuran, daya tahan, dan lamanya \\
bank dalam industri) \\
\hline 4. reputasi manajemen bank (profesionalitas) \\
KUALITAS LAYANAN \\
\hline 5. luasnya jangkauan pelayanan \\
\hline 6. pelayanan cepat \\
\hline 7. pelayanan efisien \\
\hline 8. jam operasional perbankan yang cukup \\
\hline 10. banyaknya layanan yang ditawarkan \\
\hline DAYA TARIK FISIK \\
\hline 11. tampilan luar bank \\
\hline 12. kenyamanan interior \\
\hline 13. counter dalam bank yang menarik \\
\hline 14. ketersediaan tempat parkir yang cukup luas \\
RASIONALITAS NASABAH \\
\hline 15. istilah pinjaman/ pembiayaan yang menarik \\
\hline 16. margin pinjaman/ pembiayaan yang rendah \\
\hline 17. margin/ bagi hasil/ fee dana simpanan yang tinggi/ kompetitif \\
\hline 18. biaya jasa servis transaksi bank (charge) yang rendah \\
\hline
\end{tabular}


Keputusan Penggunaan Jasa Perbankan Syariah: Perspektif Nasabah Milenial

INTERNAL BANK (KARYAWAN)

19. keramahan layanan personil bank (frontliner)

20. keterampilan karyawan bank yang baik

21. ketersediaan layanan konsultasi keuangan

22. sambutan yang diberikan oleh personil bank

LETAK LOKASI BANK

23. lokasi dekat dengan tempat tinggal

24. lokasi dekat dengan tempat aktifitas/kerja/sekolah

25. lokasi yang strategis dan mudah ditemukan

KETERSEDIAAN JARINGAN DAN TEKNOLOGI

26. ketersediaan jaringan ATM yang cukup

27. ketersediaan sms/internet/online banking

28. ketersediaan keamanan dan kecanggihan teknologi

\section{Analisis Faktor}

Dengan menggunakan bantuan SPSS versi 23, data penelitian yang dapat diproses dari 86 responden dilakukan dengan metode analisis faktor. Berikut adalah tahapannya:

\section{Uji Determinant of Correlation Matrix}

Asumsi analisis faktor pertama adalah menguji matriks korelasinya. Matrik korelasi antar variabel dinyatakan saling terkait apabila determinan bernilai mendekati nilai 0. Hasil perhitungan menunjukkan nilai Determinant of Correlation Matrix sebesar 0.00000000001691. Nilai ini mendekati 0 (nol), dengan demikian matrik korelasi antara variabel saling terkait.

\section{Uji Kaiser Meyer Olkin Measure of SamplingdanBarlett Test of Spehricity}

Asumsi analisis faktor berikutnya adalah: Kaiser Meyer Olkin Measure of Sampling (KMO) adalah indek perbandingan jarak antara koefisien korelasi dengan koefisien korelasi parsialnya. Jika jumlah kuadrat koefisen korelasi parsial di antara seluruh pasangan variabel bernilai kecil jika dibandingkan dengan jumlah kuadrat koefisien korelasi, maka akan menghasilkan nilai KMO mendekati 1. Nilai KMO dianggap mencukupi jika lebih dari 0,5. Hasil penelitian menunjukkan bahwa nilai Kaiser Meyer Olkin Measure of Sampling sebesar 0,813. Dengan demikian persyaratan KMO memenuhi persyaratan karena memiliki nilai di atas 0,5. Adapun nilai Barlett Test of Spehricity sebesar 1856.1159 dengan signifikansi sebesar 0,000. Dengan demikian Bartlett Test of Spehricity memenuhi persyaratan karena signifikansi di bawah 0,05 (5\%). Pada tabel 3, di bawah ini adalah penjelasannya: 
Tabel 3

Nilai KMO dan Bartlett's Test

KMO and Bartlett's Test

\begin{tabular}{|c|c|c|}
\hline Kaiser-Meyer-Olkin Measur & npling Adequacy. & 0.813 \\
\hline Bartlett's Test of Sphericity & Approx. Chi-Square & 1856.1159 \\
\hline & Df & 378 \\
\hline & Sig. & 0 \\
\hline
\end{tabular}

\section{Aspek Persepsi Reputasi}

Aspek pertama yang diidentifikasi dalam penelitian ini terkait penilaian kriteria pemilihan bank dari nasabah milenial aktif pengguna jasa bank syariah adalah persepsi reputasi. Total variabel indikator dalam aspek ini berjumlah 4 item. Variabel yang memiliki nilai rata-rata tertinggi yaitu reputasi keagamaan (prinsip kesesuaian syariah/menghindari riba) 4,42. Masyarakat milenial juga sangat memperhatikan kesesuaian syariah dari praktik yang dijalankan bank syariah. Hal ini tentu menjadi poin positif dari hasil upaya literasi yang telah dilakukan oleh regulasi, praktisi, dan akademisi ekonomi dan keuangan syariah selama ini . Nilai MSA dan loading komunalitas tiap variabel pada faktor ini sudah berada diatas 0,5 . Berikut pada Tabel 4, memperlihatkan nilai MSA, loading komunalitas dan rata-rata semua variabel indikator dalam Aspek Persepsi Reputasi.

Tabel 4

Nilai MSA, Loading Komunalitas dan Mean Variabel Indikator Aspek Persepsi Reputasi

\begin{tabular}{|c|c|c|c|}
\hline Aspek Persepsi Reputasi & $\begin{array}{l}\text { Nilai } \\
\text { MSA }\end{array}$ & $\begin{array}{l}\text { Nilai } \\
\text { Loading }\end{array}$ & $\begin{array}{l}\text { Nilai } \\
\text { Mean }\end{array}$ \\
\hline 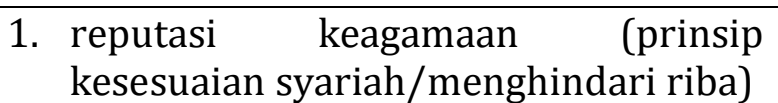 & $.682 \mathrm{a}$ & 0.65 & 4.42 \\
\hline 2. reputasi keuangan (kinerja bank) & $.782 \mathrm{a}$ & 0.78 & 4.05 \\
\hline $\begin{array}{l}\text { 3. reputasi bank (ukuran, daya tahan, } \\
\text { dan lamanya bank dalam industri) }\end{array}$ & $.905 a$ & 0.82 & 4.05 \\
\hline $\begin{array}{l}\text { 4. } \text { reputasi manajemen bank } \\
\text { (profesionalitas) }\end{array}$ & $.808 \mathrm{a}$ & 0.82 & 4.03 \\
\hline
\end{tabular}

\section{Aspek Kualitas Layanan}

Aspek kedua yang diidentifikasi dalam penelitian ini terkait penilaian kriteria pemilihan bank dari nasabah milenial aktif pengguna jasa bank syariah adalah kualitas layanan. Total variabel indikator dalam aspek ini berjumlah 6 item. Variabel yang memiliki nilai rata-rata tertinggi yaitu pelayanan cepat $(4,09)$, hal ini sejalan dengan kondisi masyarakat milenial yang hidup dalam jaman yang serba cepat (instan). Nilai MSA dan loading komunalitas tiap variabel pada faktor ini sudah berada diatas 0,5. Berikut pada Tabel 5, memperlihatkan nilai MSA, loading komunalitas dan rata-rata semua variabel indikator dalam Aspek Kualitas Layanan. 
Tabel 5

Nilai MSA, Loading Komunalitas dan Mean Variabel Indikator Aspek Kualitas Layanan

\begin{tabular}{llll}
\hline Aspek Kualitas Layanan & $\begin{array}{l}\text { Nilai } \\
\text { MSA }\end{array}$ & $\begin{array}{l}\text { Nilai } \\
\text { Loading }\end{array}$ & $\begin{array}{l}\text { Nilai } \\
\text { Mean }\end{array}$ \\
\hline 1. luasnya jangkauan pelayanan & $.831 \mathrm{a}$ & 0.77 & 4.06 \\
\hline 2. pelayanan cepat & $.844 \mathrm{a}$ & 0.84 & $\mathbf{4 . 0 9}$ \\
\hline 3. pelayanan efisien & $.793 \mathrm{a}$ & 0.88 & 4.01 \\
\hline 4. jam operasional perbankan yang cukup & $.898 \mathrm{a}$ & 0.82 & 3.91 \\
\hline 5. banyaknya layanan yang ditawarkan & $.798 \mathrm{a}$ & 0.72 & 3.94 \\
\hline 6. ketersediaan fasilitas pendukung & $.758 \mathrm{a}$ & 0.63 & 3.98 \\
\hline
\end{tabular}

\section{Aspek Daya Tarik Fisik}

Aspek ketiga yang diidentifikasi dalam penelitian ini terkait penilaian kriteria pemilihan bank dari nasabah milenial aktif pengguna jasa bank syariah adalah daya tarik fisik. Total variabel indikator dalam aspek ini berjumlah 4 item. Variabel yang memiliki nilai rata-rata tertinggi yaitu kenyamanan interior $(3,56)$. Interior kantor bank yang memberi kenyamanan sebagai salah satu physical evidence merupakan poin terpenting yang menjadi perhatian masyarakat milenial. Nilai MSA dan loading komunalitas tiap variabel pada faktor ini sudah berada diatas 0,5. Berikut pada Tabel 6, memperlihatkan nilai MSA, loading komunalitas dan rata-rata semua variabel indikator dalam Aspek Daya Tarik Fisik.

Tabel 6

Nilai MSA, Loading Komunalitas dan Mean Variabel Indikator Aspek Daya Tarik Fisik

\begin{tabular}{llll}
\hline Aspek Daya Tarik Fisik & $\begin{array}{l}\text { Nilai } \\
\text { MSA }\end{array}$ & $\begin{array}{l}\text { Nilai } \\
\text { Loading }\end{array}$ & $\begin{array}{l}\text { Nilai } \\
\text { Mean }\end{array}$ \\
\hline 1. tampilan luar bank & $.837 \mathrm{a}$ & 0.78 & 3.43 \\
\hline 2. kenyamanan interior & $.805 \mathrm{a}$ & 0.76 & $\mathbf{3 . 5 6}$ \\
\hline 3. counter dalam bank yang menarik & $.886 \mathrm{a}$ & 0.72 & 3.41 \\
\hline 4. ketersediaan tempat parker yang luas & $.901 \mathrm{a}$ & 0.73 & 3.31 \\
\hline
\end{tabular}

\section{Aspek Rasionalitas Nasabah}

Aspek keempat yang diidentifikasi dalam penelitian ini terkait penilaian kriteria pemilihan bank dari nasabah milenial aktif pengguna jasa bank syariah adalah rasionalitas nasabah. Total variabel indikator dalam aspek ini berjumlah 4 item. Variabel yang memiliki nilai rata-rata tertinggi yaitu biaya jasa servis transaksi bank (charge) yang rendah $(4,05)$. Ditengah-tengah persaingan bank yang ketat, biaya jasa menjadi pertimbangan lebih dari nasabah milenial. Nilai MSA dan loading komunalitas tiap variabel pada faktor ini sudah berada diatas 0,5. Berikut pada Tabel 7, memperlihatkan nilai MSA, loading komunalitas dan rata-rata semua variabel indikator dalam Aspek Rasionalitas Nasabah. 
Tabel 7

Nilai MSA, Loading Komunalitas dan Mean Variabel Indikator Aspek Rasionalitas Nasabah

\begin{tabular}{llll}
\hline Aspek Rasionalitas Nasabah & $\begin{array}{l}\text { Nilai } \\
\text { MSA }\end{array}$ & $\begin{array}{l}\text { Nilai } \\
\text { Loading }\end{array}$ & $\begin{array}{l}\text { Nilai } \\
\text { Mean }\end{array}$ \\
\hline $\begin{array}{l}\text { 1. istilah pinjaman/ pembiayaan yang menarik } \\
\text { 2. } \text { margin pinjaman/ pembiayaan yang rendah }\end{array}$ & 0.69 & 3.47 \\
\hline $\begin{array}{l}\text { 3. } \begin{array}{l}\text { margin/ bagi hasil/ fee dana simpanan yang } \\
\text { tinggi/ kompetitif }\end{array} \\
\begin{array}{l}\text { 4. biaya jasa servis transaksi bank (charge) } \\
\text { yang rendah }\end{array}\end{array}$ & $.693 \mathrm{a}$ & 0.75 & 3.70 \\
\hline
\end{tabular}

\section{Aspek Internal Bank/ Karyawan}

Aspek kelima yang diidentifikasi dalam penelitian ini terkait penilaian kriteria pemilihan bank dari nasabah milenial aktif pengguna jasa bank syariah adalah internal bank/karyawan. Total variabel indikator dalam aspek ini berjumlah 4 item. Variabel yang memiliki nilai rata-rata tertinggi yaitu keramahan layanan personil bank (frontliner) $(4,05)$. Sikap haangat dari petugas pelayanan bank menjadi daya tarik yang kuat bagi masyarakat milenial. Nilai MSA dan loading komunalitas tiap variabel pada faktor ini sudah berada diatas 0,5. Berikut pada Tabel 8, memperlihatkan nilai MSA, loading komunalitas dan rata-rata semua variabel indikator dalam Aspek Internal Bank/ Karyawan.

Tabel 8

Nilai MSA, Loading Komunalitas dan Mean Variabel Indikator Aspek Internal Bank/ Karyawan

\begin{tabular}{|c|c|c|c|}
\hline Aspek Internal Bank (Karyawan) & $\begin{array}{l}\text { Nilai } \\
\text { MSA }\end{array}$ & $\begin{array}{l}\text { Nilai } \\
\text { Loading }\end{array}$ & $\begin{array}{l}\text { Nilai } \\
\text { Mean }\end{array}$ \\
\hline 1. keramahan layanan personil bank (frontliner) & $.821 \mathrm{a}$ & 0.68 & 4.05 \\
\hline 2. keterampilan karyawan bank yang baik & $.903 a$ & 0.70 & 3.83 \\
\hline 3. ketersediaan layanan konsultasi keuangan & $.800 \mathrm{a}$ & 0.72 & 3.72 \\
\hline 4. sambutan yang diberikan oleh personil bank & $.797 a$ & 0.70 & 3.91 \\
\hline
\end{tabular}

\section{Aspek Letak Lokasi Bank}

Aspek keenam yang diidentifikasi dalam penelitian ini terkait penilaian kriteria pemilihan bank dari nasabah milenial aktif pengguna jasa bank syariah adalah letak lokasi bank. Total variabel indikator dalam aspek ini berjumlah 3 item. Variabel yang memiliki nilai rata-rata tertinggi yaitu lokasi dekat dengan tempat aktifitas/kerja/sekolah $(3,91)$. Masyarakat milenial saat ini sebagian besar waktunya digunakan untuk aktivitas/bekerja ataupun belajar.Untuk itu lokasi yang menarik bagi mereka adalah yang mendekati tempat aktivitasnya. Nilai MSA dan loading komunalitas tiap variabel pada faktor ini sudah berada diatas 0,5. Berikut pada Tabel 9, memperlihatkan 
nilai MSA, loading komunalitas dan rata-rata semua variabel indikator dalam Aspek Letak Lokasi Bank.

\begin{tabular}{|c|c|c|c|}
\hline \multicolumn{4}{|c|}{$\begin{array}{c}\text { Tabel } 9 \\
\begin{array}{c}\text { Nilai MSA, Loading Komunalitas dan Mean Variabel Indikator } \\
\text { Aspek Letak Lokasi Bank }\end{array}\end{array}$} \\
\hline Aspek Letak Lokasi Bank & $\begin{array}{l}\text { Nilai } \\
\text { MSA }\end{array}$ & $\begin{array}{l}\text { Nilai } \\
\text { Loading }\end{array}$ & $\begin{array}{l}\text { Nilai } \\
\text { Mean }\end{array}$ \\
\hline 1. lokasi dekat dengan tempat tinggal & & 0.50 & 3.83 \\
\hline $\begin{array}{l}\text { 2. lokasi dekat dengan tempat aktifitas/ } \\
\text { kerja/ sekolah }\end{array}$ & $.800 \mathrm{a}$ & 0.64 & 3.91 \\
\hline $\begin{array}{l}\text { 3. lokasi yang strategis dan mudah } \\
\text { ditemukan }\end{array}$ & $.801 \mathrm{a}$ & 0.71 & 3.84 \\
\hline
\end{tabular}

\section{Aspek Ketersediaan Jaringan dan Teknologi}

Aspek ketujuh yang diidentifikasi dalam penelitian ini terkait penilaian kriteria pemilihan bank dari nasabah milenial aktif pengguna jasa bank syariah adalah ketersediaan jaringan dan teknologi. Total variabel indikator dalam aspek ini berjumlah 3 item. Variabel yang memiliki nilai rata-rata tertinggi yaitu ketersediaan SMS/internet/online banking $(4,24)$. Masyarakat milenial relatif melek teknologi dan sebagian besar mereka menggunakan jasa internet untuk mendukung berbagai aktivitasnya termasuk ketika harus bertransaksi di bank. Dengan demikian sangat diperlukan ketersediaan fasilitas SMS/internet/online banking bagi suatu bank dalam memberikan jasanya. Nilai MSA dan loading komunalitas tiap variabel pada faktor ini sudah berada diatas 0,5. Berikut pada Tabel 10, memperlihatkan nilai MSA, loading komunalitas dan rata-rata semua variabel indikator dalam Aspek Jaringan dan Teknologi.

Tabel 10

Nilai MSA, Loading Komunalitas dan Mean Variabel Indikator Aspek Ketersediaan Jaringan dan Teknologi

\begin{tabular}{llll}
\hline Aspek Ketersediaan Jaringan dan Teknologi & $\begin{array}{l}\text { Nilai } \\
\text { MSA }\end{array}$ & $\begin{array}{l}\text { Nilai } \\
\text { Loading }\end{array}$ & $\begin{array}{l}\text { Nilai } \\
\text { Mean }\end{array}$ \\
\hline 1. ketersediaan jaringan ATM yang cukup & $.790 \mathrm{a}$ & 0.80 & 4.02 \\
\hline 2. ketersediaan SMS/internet/online banking & $.715 \mathrm{a}$ & 0.58 & $\mathbf{4 . 2 4}$ \\
\hline $\begin{array}{l}\text { 3. } \\
\text { ketersediaan keamanan dan kecanggihan } \\
\text { teknologi }\end{array}$ & $.806 \mathrm{a}$ & 0.68 & 4.15 \\
\hline
\end{tabular}

Berdasarkan data-data diatas, dapat disimpulkan bahwa semua variabel secara simultan telah memenuhi syarat validitas (nilai KMO $=0,813$ ), semua variabel secara masing-masing telah memenuhi syarat reabilitas (nilai MSA > $0,5)$ dan semua variabel secara masing-masing telah memenuhi syarat komunalitas (nilai loading $>0,5$ ). Dengan demikian bahwa 28 variabel yang menjadi indikator dari 8 aspek, mampu menerangkan kriteria pemilihan 
bank menurut responden dari nasabah milenial aktif pengguna jasa bank syariah.

\section{Analisis Mean dan Penentuan Peringkat Faktor}

Untuk memberikan pemahaman lebih lanjut terkait masalah penelitian, ketujuh aspek tersebut dicari peringkat faktornya dengan menghitung nilai komposit.Nilai komposit dihitung dengan membagi rata-rata total dari setiap item yang dimuat dalam aspek dengan jumlah item yang dimuat dalam aspek masing-masing. Aspek yang dominan dalam penelitian ini terkait penilaian kriteria pemilihan bank dari nasabah milenial aktif pengguna jasa bank syariah secara berurutan adalah persepsi reputasi $(4,14)$ dan ketersediaan jaringan dan teknologi $(4,14)$, kualitas layanan $(3,998)$ dan internal bank (karyawan) $(3,878)$. Data lebih jelasnya dapat dilihat pada Tabel 11:

Tabel 11

Prioritas Aspek

\begin{tabular}{lllll}
\hline Aspek & $\begin{array}{c}\text { Total } \\
\text { Mean }\end{array}$ & $\begin{array}{l}\text { Jumlah } \\
\text { Variabel }\end{array}$ & $\begin{array}{l}\text { Nilai } \\
\text { Komposit }\end{array}$ & Peringkat \\
\hline Persepsi Reputasi & 16.55 & 4 & $\mathbf{4 . 1 4}$ & 1 \\
\hline $\begin{array}{l}\text { Ketersediaan Jaringan dan } \\
\text { Teknologi }\end{array}$ & 12.41 & 3 & $\mathbf{4 . 1 4}$ & 1 \\
\hline Kualitas Layanan & 23.99 & 6 & 4.00 & 2 \\
\hline Internal Bank/ Karyawan & 15.51 & 4 & 3.88 & 3 \\
\hline Letak Lokasi Bank & 11.58 & 3 & 3.86 & 4 \\
\hline Rasionalitas Nasabah & 14.99 & 4 & 3.75 & 5 \\
\hline Daya Tarik Fisik & 13.71 & 4 & 3.43 & 6 \\
\hline
\end{tabular}

Berdasarkan hasil analisis, beberapa rekomendasi untuk penguatan persepsi masyarakat milenial yang dapat dirumuskan adalah: pertama, meningkatkan intensifitas program literasi keuangan syariah. Berdasarkan hasil bahwa keputusan masyarakat milenial dalam menggunakan jasa bank syariah mayoritas atas inisiatif diri sendiri, maka diperlukan peningkatan intensifitas program literasi keuangan syariah khususnya literasi perbankan syariah agar masyarakat milenial semakin banyak yang tertarik menjadi pengguna jasa bank syariah.Kemudian yang perlu disasar oleh bank syariah adalah kerjasama dengan lembaga/institusi kerja karena masyarakat milenial juga menggunakan bank syariah atas referensi atasan/tempat kerja.

Kedua, menjaga reputasi kesesuaian syariah. Nasabah milenial aktif pengguna jasa bank syariah dalam kriteria pemilihan bank, dominan mempertimbangkan aspek persepsi reputasi terutama reputasi keagamaan (prinsip kesesuaian syariah/menghindari riba). Untuk itu, bank syariah juga harus terus menjaga reputasi terutama reputasinya dalam menjalankan kegiatan bank syariah sesuai dengan prinsip-prinsip syariah.Jangan sampai tujuan bisnis menyebabkan bank syariah lalai dari menjaga kesesuaian prinsip syariahnya. 
Ketiga, meningkatkan ketersediaan jaringan dan teknologi baik secara internal maupun bersinergi dengan bank syariah atau lembaga IKNB (Institusi Keuangan Non Bank) syariah lainnya serta Perusahaan Tekonologi Keuangan (Fintek). Kriteria lain bagi nasabah milenial aktif pengguna jasa bank syariah dalam pemilihan bank berikutnya juga mempertimbangkan aspek ketersediaan jaringan dan teknologi terutama ketersediaan sms/internet/online banking. Kriteria berikutnya adalah aspek kualitas layanan terutama pelayanan cepat. Dengan demikian perlu ada upaya secara individual bank maupun sinergisitas dengan institusi lainnya dalam penyediaan jaringan dan teknologi dengan ketersediaan layanan sms/ internet/online banking serta teknologi yang dapat meningkatkan efisiensi, kecepatan dan luasnya jangkauan pelayanan bank syariah seperti membuat jaringan ATM, kartu E-Money, mesin EDC bank syariah bersama, aplikasi digital banking, dan berkerjasama dengan Perusahaan Fintek baik Fintek Pembayaran dan Fintek Toko Online/market place.

Ke-empat, meningkatkan keramahan petugas pelayanan dan kenyamanan ruang pelayanan. Nasabah milenial aktif pengguna jasa bank syariah juga mempertimbangkan kualitas SDM bank dalam memberikan layanan yang bersahabat dan keterampilan karyawan bank tersebut. Dengan demikian perlu ada upaya peningkatan kuantitas pelatihan SDM bank yang berkualitas dalam pemberian layanan dan peningkatan kompetensi personil. Juga diperlukan peningkatan dalam tampilan fisik dan non fisik ruang pelayanan agar lebih nyaman bagi nasabah milenial.

Terakhir, nengurangi biaya jasa dalam transaksi bank syariah. Hal ini perlu dilakukan agar bank syariah dapat lebih kompetitif dibandingkan dengan bank konvensional. Untuk itu, bank syariah harus lebih meningkatkan efisiensi dalam kegiatan operasinya agar dapat membebankan biaya yang relatif ringan bagi nasabahnya, karena bank syariah akan berhadapan dengan bank konvensional yang umumnya memberikan biaya transaksi lebih rendah.

\section{Keterbatasan dan Agenda Penelitian Berikutnya}

Keterbatasan dari penelitian ini terkait jumlah responden penelitian tidak banyak dan hanya mengambil sampel nasabah aktif Bank Umum Syariah di wilayah Jabodetabek. Penelitian lebih lanjut dapat diperluas berdasarkan kriteria demografi lain seperti gender dan pekerjaan, dengan jumlah responden yang lebih besar dan cakupan wilayah yang lebih luas.

\section{SIMPULAN}

Berdasarkan hasil dan pembahasan diperoleh kesimpulan sebagai berikut: pertama, pihak yang mempengaruhi masyarakat milenial dalam pengambilan keputusan menggunakan jasa perbankan syariah mayoritas yaitu atas inisiatif diri sendiri. Kedua, aspek dominan yang mempengaruhi masyarakat milenial dalam pengambilan keputusan menggunakan jasa perbankan syariah adalah persepsi reputasi dan ketersediaan jaringan dan teknologi. Sub aspek dari persepsi reputasi yang dominan adalah reputasi keagamaan 
(prinsip kesesuaian syariah/menghindari riba). Sub aspek ketersediaan jaringan dan teknologi yang dominan adalah ketersediaan SMS/internet/online banking.

\section{DAFTAR PUSTAKA}

Abdullah, A.A. Sidek, R. Adnan, A.A. (2012). Perception of non-muslims customers towards islamic banks in malaysia. International Journal of Business and Social Science.Vol 3 No. 11, 2012.

Abhimantra, A. Maulina, A.R. Agustianingsih, E. (2013). Analisis faktor-faktor yang mempengaruhi nasabah (mahasiswa) dalam memilih menabung pada bank syariah. Prosiding PESAT (Psikologi, Ekonomi, Sastra, Arsitektur \& Teknik Sipil), 8-9 Oktober 2013.

Adawiyah, W.R. (2010). Pertimbangan, pengetahuan, dan sikap konsumen individu terhadap bank syariah. Jurnal Ekonomi Pembangunan. Vol. 11 (2): 191-201.

Ahmad, K. Rustam, G.A. Dent, M.M. (2011). Brand preference in Islamic banking. Journal of Islamic Marketing. Vol. 2 (1): 74-82.

Ali, Hasanuddin, dkk. 2017. The Urban Middle-Class Millenials Indonesia : Financial and Online Behavior. Jakarta : PT Alvara Strategi Indonesia.

Awan, H. M., \& Shahzad Bukhari, K. (2011). Customer's criteria for selecting an Islamic bank: evidence from Pakistan. Journal of Islamic marketing, 2(1), 14-27.

Hasan, S. A., Subhani, M. I., \& Osman, M. (2012). Consumer criteria for the selection of an Islamic Bank: Evidence from Pakistan.

Hana, K. F. (2018). Faktor-Faktor Yang Mempengaruhi Keputusan Non Muslim Menjadi Anggota Pada KSPPS Fastabiq Khoiru Ummah Pati. MALIA: Journal of Islamic Banking and Finance, 2(2), 189-200. Retrieved from http://journal.stainkudus.ac.id/index.php/syirkah/index

Lateh, N., Ismail, S., \& Ariffin, N. M. (2009). Customers' perceptions on the objectives, characteristics and selection criteria of Islamic bank in Thailand. Gadjah Mada International Journal of Business, 11(2), 167189.

Mansour, W. Abdelhamid, M.B. Masood, O. Niazi, G.S.K. (2010). Islamic banking and customers' preferences: the case of the UK. Qualitative Research in Financial Markets.Vol 2. (3): 185-199.

Marimuthu, M. Jing, C.W. Gie, L.P. Mun, L.P. Ping, T.Y. (2010). Islamic banking: selection criteria and implications. Global Journal of Human Social Science. Vol. 10 No. 4, 2010

[OJK] Otoritas Jasa Keuangan. (2018). Laporan publikasi statistik perbankan syariah. Jakarta.

Pinar, M. Girard, T. Eser, Z. (2012). Consumer-based brand equity in banking industry: a comparison of local and global banks in Turkey. International Journal of Bank Marketing. Vol. 30 (5): 359-375. 
Keputusan Penggunaan Jasa Perbankan Syariah: Perspektif Nasabah Milenial

[RI]. Republik Indonesia.(2008). Undang-Undang No. 21 Tahun 2008 Tentang Perbankan Syariah.

Sari, Y. Sumarwan, U. Hosen, M.N. (2016).Analisis faktor-faktor preferensi Etnis Tionghoa Terhadap Bank Syariah di Indonesia. Jurnal AlMuzara'ah. Vol. 3 No. 1, 2016.

Sudarsono H. (2008). Bank dan Lembaga Keuangan Syariah. Deskripsi dan Ilustrasi.Yogyakarta(ID): EKONISIA.

Tamimi, H.A.H. Kalli, A.A.B. (2009). Financial literacy and investment decisions of UAE. The Journal of Risk Finance. Vol.10 No. 5, 2009. 
Ida Syafrida, Aminah dan Taufik Awaludin

Halaman ini sengaja di kosongkan 